\title{
A multi-hazards earth science perspective on the COVID-19 pandemic: the potential for concurrent and cascading crises
}

\author{
Mark C. Quigley ${ }^{1,2}\left[\right.$. Januka Attanayake ${ }^{1}$. Andrew King $^{1,3} \cdot$ Fabian Prideaux ${ }^{4}$
}

Published online: 16 May 2020

(c) Springer Science+Business Media, LLC, part of Springer Nature 2020

\begin{abstract}
Meteorological and geophysical hazards will concur and interact with coronavirus disease (COVID-19) impacts in many regions on Earth. These interactions will challenge the resilience of societies and systems. A comparison of plausible COVID19 epidemic trajectories with multi-hazard time-series curves enables delineation of multi-hazard scenarios for selected countries (United States, China, Australia, Bangladesh) and regions (Texas). In multi-hazard crises, governments and other responding agents may be required to make complex, highly compromised, hierarchical decisions aimed to balance COVID19 risks and protocols with disaster response and recovery operations. Contemporary socioeconomic changes (e.g. reducing risk mitigation measures, lowering restrictions on human activity to stimulate economic recovery) may alter COVID-19 epidemiological dynamics and increase future risks relating to natural hazards and COVID-19 interactions. For example, the aggregation of evacuees into communal environments and increased demand on medical, economic, and infrastructural capacity associated with natural hazard impacts may increase COVID-19 exposure risks and vulnerabilities. COVID-19 epidemiologic conditions at the time of a natural hazard event might also influence the characteristics of emergency and humanitarian responses (e.g. evacuation and sheltering procedures, resource availability, implementation modalities, and assistance types). A simple epidemic phenomenological model with a concurrent disaster event predicts a greater infection rate following events during the pre-infection rate peak period compared with post-peak events, highlighting the need for enacting COVID-19 counter measures in advance of seasonal increases in natural hazards. Inclusion of natural hazard inputs into COVID-19 epidemiological models could enhance the evidence base for informing contemporary policy across diverse multi-hazard scenarios, defining and addressing gaps in disaster preparedness strategies and resourcing, and implementing a future-planning systems approach into contemporary COVID-19 mitigation strategies. Our recommendations may assist governments and their advisors to develop risk reduction strategies for natural and cascading hazards during the COVID-19 pandemic.
\end{abstract}

Keywords Coronavirus $\cdot$ COVID-19 $\cdot$ Natural disasters $\cdot$ Decision-making $\cdot$ Multi-hazards

\section{Introduction}

Electronic supplementary material The online version of this article (https://doi.org/10.1007/s10669-020-09772-1) contains supplementary material, which is available to authorized users.

Mark C. Quigley

mark.quigley@unimelb.edu.au

1 School of Earth Sciences, University of Melbourne, Parkville, VIC 3010, Australia

2 School of Earth and Environment, University of Canterbury, Christchurch 8004, New Zealand

3 ARC Centre of Excellence for Climate Extremes, University of Melbourne, Parkville, VIC 3010, Australia

4 Humanitarian Benchmark Consulting (HBC), Oxford, UK
The severe acute respiratory syndrome coronavirus 2 (SARS-CoV-2) and its associated coronavirus disease (COVID-19) emerged from probable zoonotic origin from China's Hubei province in early December 2019. The virus and disease are collectively referred to as COVID-19 in this paper. COVID-19 rapidly spread around the world and was declared a pandemic by the World Health Organization (WHO) on 11 March 2020 (https://www.who.int/emergencie s/diseases/novel-coronavirus-2019/events-as-they-happen). As of 29 April 2020, the John Hopkins University coronavirus dashboard (https://coronavirus.jhu.edu/map.html) 
reports more than 3.1 million confirmed infections and more than 217,200 fatalities globally.

This paper uses quantitative and qualitative measures to assess the likelihood of natural hazards coinciding with, and influencing epidemiological characteristics of, the COVID-19 pandemic. Natural hazard curves for seasonal (e.g. tropical cyclone, floods, heat waves, monsoons, tornadoes) hazards are plotted against COVID-19 time-series forecasts (Fig. 1). Stochastic (e.g. earthquakes, volcanic eruptions) hazards are also considered in a general sense but not specifically analysed. The effects of these natural hazards on human life depends on the severity of the hazard,

\section{(a) United States}

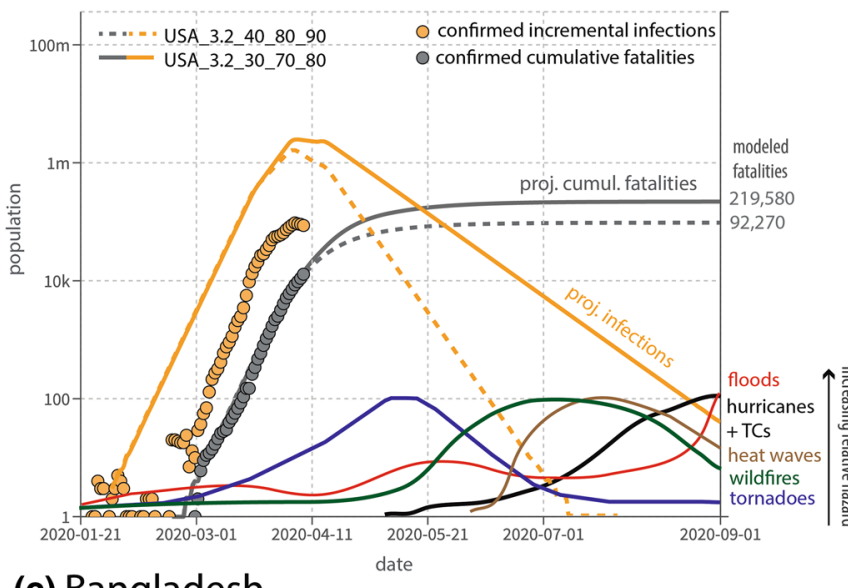

(c) Bangladesh

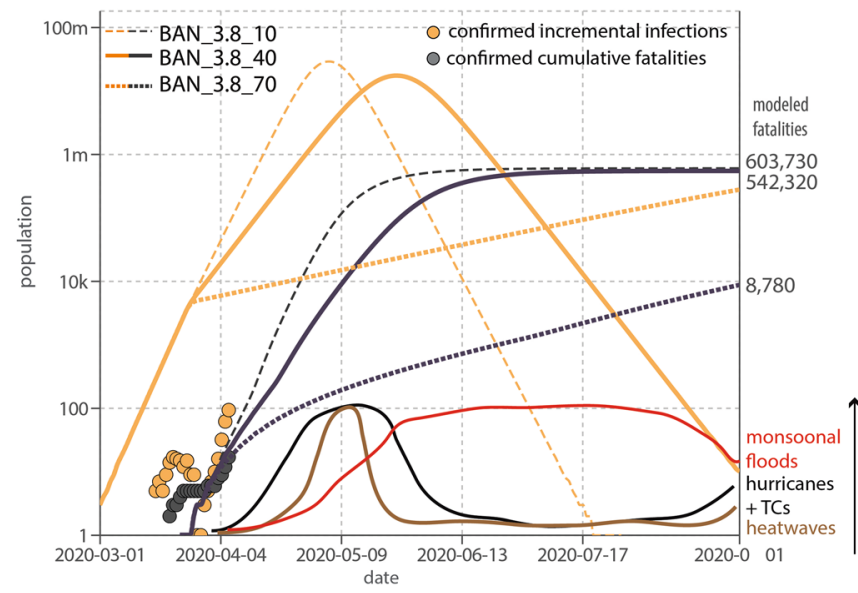

Fig. 1 Epidemiological forecast models for COVID-19 fatalities and infections for a the United States, b Australia, c Bangladesh and d China, developed using https://covid19-scenarios.org/ software and boot-strapping reproduction number $(1.9 \leq \mathrm{Ro} \leq 3.2)$, simulation date ranges, and \% mitigation estimate parameters (see legend in each panel) to maximize goodness-of-fit between confirmed cumulative fatalities and model curves. Epidemiological curves are labelled in the format COUNTRY_AVERAGE Ro_MITIGATION\#1\%EFFECT IVENESS_tMITIGATION\#2\%EFFECTIVENESS_+MITIGATION \#3\%EFFECTIVENESS. Epidemiological curves are subject to large and spatiotemporally varying uncertainties and are thus intended for the exposure of humans and infrastructure to it, the vulnerability of exposed elements, and the ability to respond and recover. COVID-19 has the potential to significantly impact the exposure, vulnerability and response elements associated with natural disasters and vice-versa, thereby requiring a systems approach to analyse risk and resilience (e.g. Simonovic 2011; Harrison and William 2016).

Approaches to mitigating COVID-19 risks share some commonalities with natural disaster mitigation. For example, enacting social distancing protocols to reduce COVID-19 exposure could be considered analogous to land-use planning to reduce exposure to natural hazards (e.g. floods,

\section{(b) Australia}

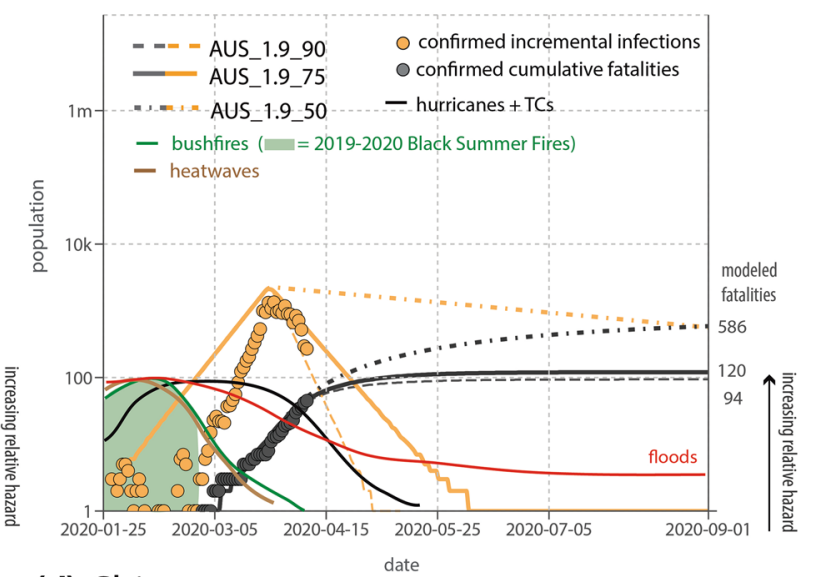

(d) China

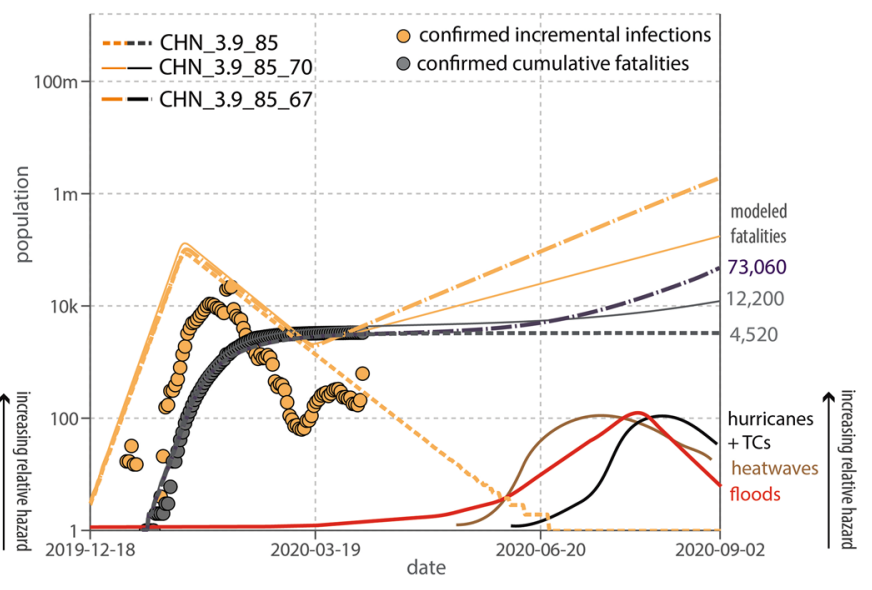

illustrative purposes only, rather than accurate and precise forecasts. The grey box in (a) is the $95 \%$ confidence interval for the Institute for Health Metrics and Evaluation U.S. cumulative fatality projection with preferred value (black line). Model parameters and results for a-d are presented in the Supplementary Information accompanying this paper. Representative seasonal hazard curves for each country as shown. TCs tropical cyclones. See text for interpretations. These hazard curves are derived from a variety of sources (Brooks et al. 2003; Landsea 1993; Nissan et al. 2017; Sheridan and Kalkstein 2010) and expert knowledge 
earthquakes) (Quigley et al. 2020). COVID-19 health and service policies aimed to preference vulnerable groups including the elderly, those with ill health and comorbidities, the homeless or underhoused, and people from vulnerable socioeconomic groups that might be vulnerable to financial, psychosocial and/or physical challenges (Lancet 2020), are crudely analogous to defining and enforcing seismic building codes, and strengthening earthquake-vulnerable buildings, to reduce life safety risks (e.g. Stucchi et al. 2011; Hosseini et al. 2009).

Epidemiological forecasts of COVID-19 infections and fatalities (Fig. 1) exhibit large spatial and temporal variations due to differences in modelling approaches, mitigation scenarios (e.g. "Supress and Lift" strategy used in Hong Kong and Singapore; see Normile 2020), health system capacity, epidemiological parameters, and demographic parameters (https://covid19-scenarios.org/). Changes induced by external (e.g. the concurrency of other emergent phenomena such as natural disasters) and internal factors (e.g. relaxation of social distancing measures, return-to-work decisions) can impact on many of these parameters significantly and thus create more uncertainty in infection and fatality predictions (Fig. 1). It is therefore challenging to define what a 'worsecase' COVID-19 fatality scenario is, given the susceptibility of forecasts to major perturbations induced by phenomena with uncertain spatial and temporal properties.

Given this context, resolving policy priorities in response to the COVID-19 pandemic and associated compounding effects of natural hazards involves a complex higher-level decision-making process that must inevitably be guided by scientific insight (Colwell and Machlis 2019; Filippelli 2020). In view of this, our study seeks to provide a qualitative analysis of the combined effect of COVID-19 epidemic and external perturbations, specifically natural disasters, to propose that:

(i) COVID-19 epidemiological models may be highly sensitive to disasters originating from natural hazards, and thus inclusion of seasonal and / or stochastic events might better enable worst-case scenarios to be considered,

(ii) contemporary COVID-19 related policies, such as relaxations of mitigative measures, may increase the probability that diverse multi-hazards will interact with the COVID-19 crisis and stimulate concurrent and cascading crises, and

(iii) disaster preparedness strategies and resourcing should carefully consider the impact of COVID-19 on future response operations, including: adaptation of implementation modalities to account for the disruption of critical supply chains, the potential localisation of response efforts due to limited mobility of humanitarian actors, availability of evacuation cen- tres with capacity for social distancing, the capacity of humanitarian workers/volunteers and medical staff to respond to natural disasters in COVID-affected regions, and the availability of personal protective equipment and medical equipment (e.g. respirators) to incorporate large spikes in need.

\section{Context: cascading natural disasters and their relevance to COVID-19 scenarios}

In this paper, we forthwith use the term 'natural disaster' to refer to an adverse event or series of events that originate from the interaction of hazardous event(s) of natural origin with humans and/or their physical and/or socioeconomic systems and infrastructure. Droughts, floods (meteorological) and earthquakes (geophysical) are the most common natural disasters in the world, affecting millions of people every year (Kouadio et al. 2012). Natural disaster fatalities since 1900 reveal decreases in average annual deaths from major drought and flood events and increases in fatalities associated with earthquakes (including tsunamis) and extreme weather (e.g. tornadoes, tropical cyclones) and temperature events (e.g. heat waves) (Fig. 2). Fatality estimates from extreme temperature events are considered a minimum value because heat and cold temperature extremes may exacerbate pre-existing medical conditions and contribute to mortality rates without formal attribution (Medina-Ramon et al. 2006).

A concurrent hazard is defined herein as hazardous event(s) of natural physical (e.g. earthquake, volcanic eruption, flood, tropical cyclone) or biologic origin (e.g. an infectious disease such as COVID-19) that overlap in time and space. The occurrence of two or more hazardous events (e.g. an earthquake during COVID-19) is referred to here as a multi-hazard scenario [a.k.a. "compound events", although this term has a broader definition than used here (e.g. Zscheischler et al. 2018)]. Hazards that are sourced from, triggered by, and/or influenced by preceding hazards are referred to as cascading hazards. For context, we provide brief examples below.

On January 12, 2010, a catastrophic 7.0 magnitude earthquake struck Haiti, causing more than 200,000 fatalities, displacing more than 1.5 million people, and affecting 3 million people overall (Doocy et al. 2013, see also Fig. 2). The earthquake severely damaged the public sanitation system and created ideal conditions for outbreaks of major infectious diseases. Nine months later, a cholera outbreak originating from human transmission (Orata et al. 2014) began to spread across the country, eventuating in more than 9000 deaths and 650,000 infections (https://www.cdc.gov/chole $\mathrm{ra} /$ haiti/index.html). Prior to 2010 , there was no reported history of cholera in Haiti. Long-term impacts and hazards 


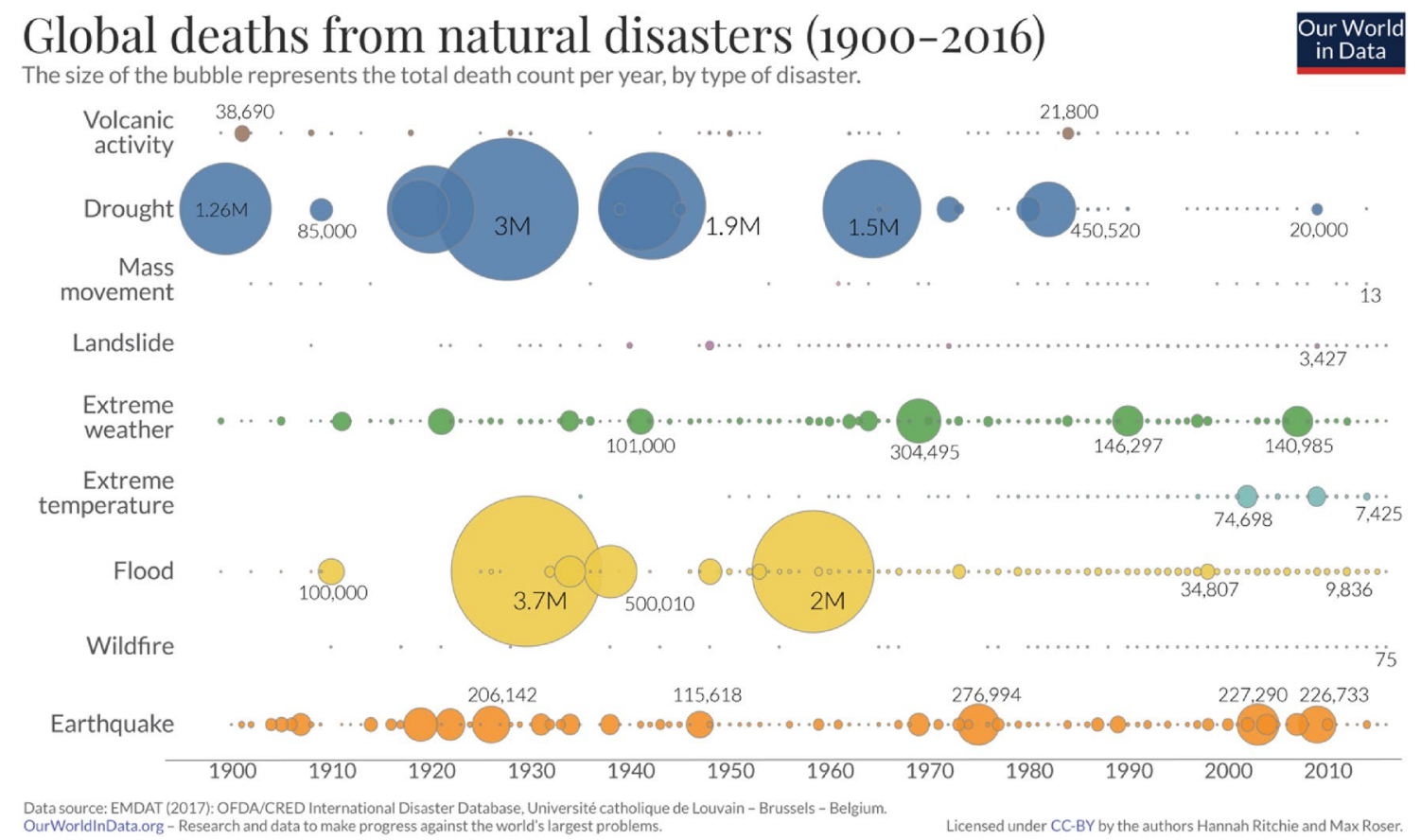

Fig. 2 Average annual deaths by natural disasters (Ritchie and Roser 2020)

originating from the earthquake crisis (socioeconomic impacts, infrastructure impacts, hazards such as aftershocks) spatially and temporally overlapped, interacted with, and amplified the cholera impacts; these could be considered as a protracted multi-hazard scenario with cascading elements and disastrous impacts.

Other cascading, multi-hazard examples include:

(i) increased long-term flood hazard in Christchurch, New Zealand caused by, and concurrent with, the 20102011 Canterbury earthquake sequence (Quigley and Duffy 2020) caused significant damage to property and infrastructure and increased vulnerability to coastaltidal hazards,

(ii) large death tolls in Puerto Rico and some Caribbean islands due to the cascading effects of Hurricanes Irma and Maria compounded societal vulnerability through infrastructure damage and power outages that left millions without electricity, water, and cell phone service for 2-4 weeks;

(iii) the 2015 magnitude 7.8 Nepal earthquake along with its magnitude 7.3 aftershock triggered snow avalanches (largest $\sim 2.3 \mathrm{~km}^{2}$ ) and thousands of landslides, the latter of which caused flooding due to river blockages and landslide dam breaches (Martha et al. 2017). Blocked and damaged road infrastructure directly impacted earthquake response efforts, including search and rescue activities, the timely provision of emergency aid, the ability to conduct rapid needs assessments, and the provision of essential services (Khazai et al. 2015). The complex spatial distribution of landslides highlights the need for considering additional dimensions including seasonality in a multi-hazard scenario (Roback et al. 2018);

(iv) extreme events (e.g. floods of 1987, 1998, and 2007, tropical cyclone in 1991) in Bangladesh that offer a perspective of the interaction between extreme natural hazards and socioeconomic vulnerabilities, and how that could be amplified by COVID-19 (Siddique et al. 1991; Khalil 1993; Mushtaque et al. 1993; Dove and Khan 1995; Chowdhury 2000; Benson and Clay 2002; Mirza 2002; Sherman and Shapiro 2005; McMahon 2007; Zoraster 2010; Rahman et al. 2013).

(v) the 2011 Tohoku magnitude 9.1 earthquake, which caused shaking damage, triggered a tsunami with disastrous impacts, including a major malfunction at the Fukushima Daiichi Nuclear Power Plant that exposed people to severe radiation hazards locally and significant hazards globally (Ten Hoeve and Jacobson 2012).

It is also pertinent to consider hazard cascades with epidemic components. For instance, previous cases of Acute Respiratory Infections (ARIs) following natural disasters can shed light on disaster response needed to counter the spread of COVID-19. ARIs were a major concern following natural disasters such as the South Asian Tsunami (World Health Organization 2005; Doocy et al. 2007), major-togreat earthquakes (Weekly Morbidity and Mortality Report 
Pakistan, Vol. 42/ DEWS 2006-36; Woersching and Snyder 2004; Akbari et al. 2004), volcanic eruptions (Surmieda et al. 1992), and hurricanes (Campanella 1999). Outbreaks of other communicable diseases (e.g. water borne diseases) in communities affected by natural disasters are commonly attributed to crowding of displaced people in camps (Weekly Morbidity and Mortality Report Pakistan, Vol. 23/DEWS 2006-2017; Marin et al. 2006; Watson et al. 2007; Kouadio et al. 2012).

Several natural disasters have now occurred during the COVID-19 crisis. We consider some of these in Sects. 3 and 4. Many countries around the world, including those with increasing COVID-19 infection and fatality rates are highly susceptible to seasonal natural disasters. Some decision-makers have reduced (or are considering reduction of) COVID-19 mitigation measures based on epidemiologic data and/or priority valuation of other inputs (e.g. economic, political). The likelihood of future natural disasters and potential impacts on COVID-19 exposure and vulnerability is scarcely mentioned in these narratives.

\section{Plausible COVID-19 epidemic scenarios, multi-hazard curves, and the importance of expeditiously reducing infection rates prior to disaster seasons}

Figure 1 presents epidemiological forecast models for COVID-19 fatalities and infections for the USA, Australia, Bangladesh and China, developed using https://covid 19-scenarios.org/ Software. Curves were generated by iteratively bootstrapping the COVID reproduction number
$\left(R_{\mathrm{o}}\right)$, simulation onset date, and \% mitigation variables to maximize goodness-of-fit between confirmed cumulative fatalities and modelled deaths through the same time period. Several alternative scenarios were considered by adjusting the $\%$ mitigation variable only.

The average $R_{\mathrm{o}}$ ranges from 1.9 (Australia) to 3.9 (China); Bangladesh is 3.8 and the United States is 3.2. These estimates are consistent with the range of reported $R_{\mathrm{o}}$ values from scientific literature (https://www.nature.com/articles/ d41586-020-01003-6); noting that the $R_{\mathrm{o}}$ values used here are intended to be an average value since COVID-19 onset (rather than a value representing the current situation) that are modified by adjusting the $\%$ mitigation parameter at various time-slices. Mitigation dates for each country were derived from internet media reports by searching "country name", and "COVID-19 mitigation actions" in Google and Google news search engines. The mitigation \% effectiveness parameter was estimated from our analysis of the mitigation protocols taken, as represented by the media consulted for mitigation dates. A preference was given to peer-reviewed literature and/or government-issued information sources. For example, in Australia, we assigned a mitigation estimate of $75 \%$ (range 50\% to $90 \%$ effectiveness) commencing on 23 March 2020, when many places of social gathering were closed and a variety of mitigation strategies aimed to reduce social contact were progressively enacted, based on a government source summary document (https://www.healt h.gov.au/news/health-alerts/novel-coronavirus-2019-ncovhealth-alert/how-to-protect-yourself-and-others-from-coron avirus-covid-19/limits-on-public-gatherings-for-coronaviru s-covid-19). Some countries have highly incremented and highly regionalized mitigation processes (https://www.cdc.

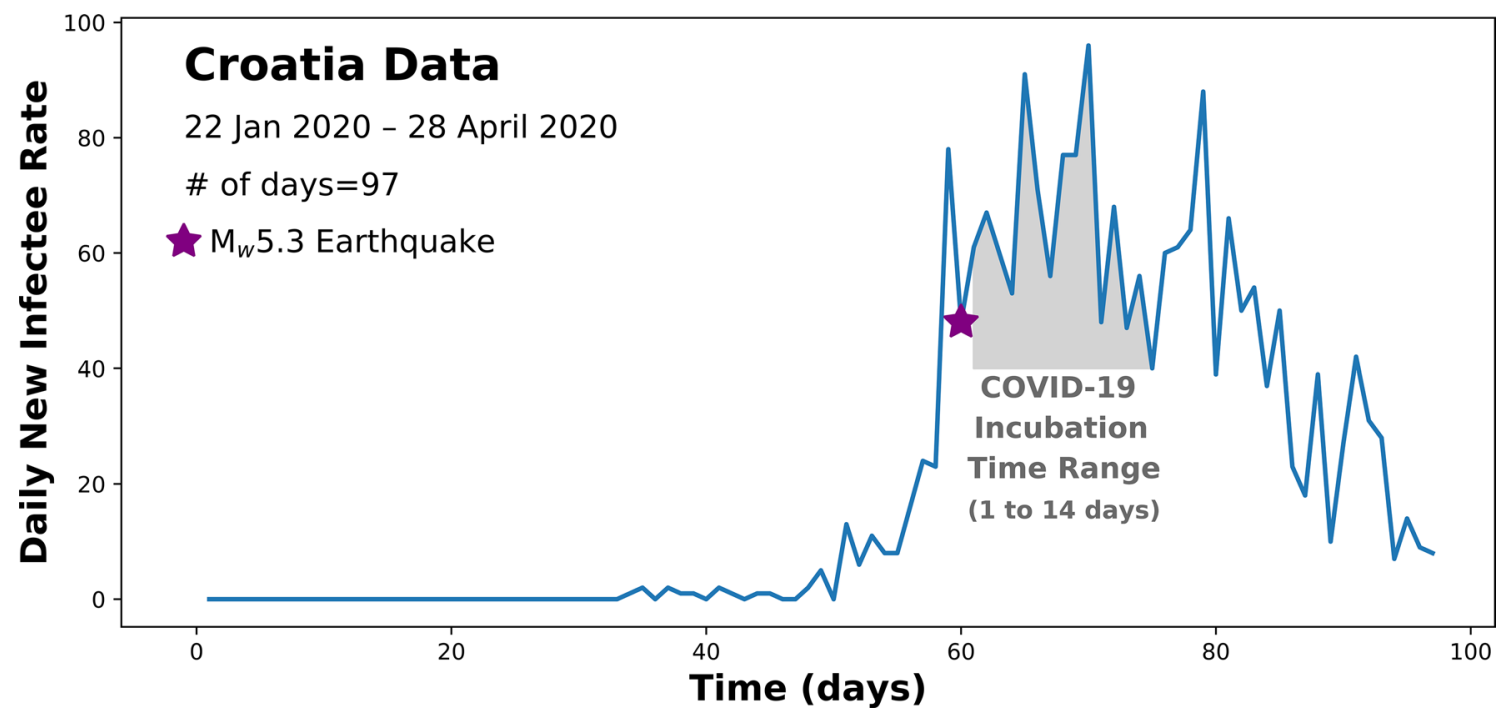

Fig. 3 Daily new infectee rate in Croatia. The time of the Mw 5.3 Zagreb earthquake is also shown along with the COVID-19 incubation time range defined by WHO. An apparent increase in the infectee rate proceeding the earthquake is discernible. Data source Dong et al. (2020) 
Fig. 4 Illustrations of cumulative infectees and daily new infectee rates. Upper panel: Reported confirmed COVID-19 cases in China from 22 January to 28 April 2020 (blue curve) and the model based on Eq. (1) (red-dashed line; see Sect. 5 for equation). See main text for parameters used. Bottom panel: An example model output (see main text for details) showing the daily new infectee rate over time for larger (blue) and smaller (red) spreading rates. While the infected population size $\left(N_{\max }=10,000\right)$ remains the same, a reduction in spreading rate from $g=0.2$ (blue curve) to $g=0.1$ (red curve) "flattens the curve" over a time horizon of 150 days
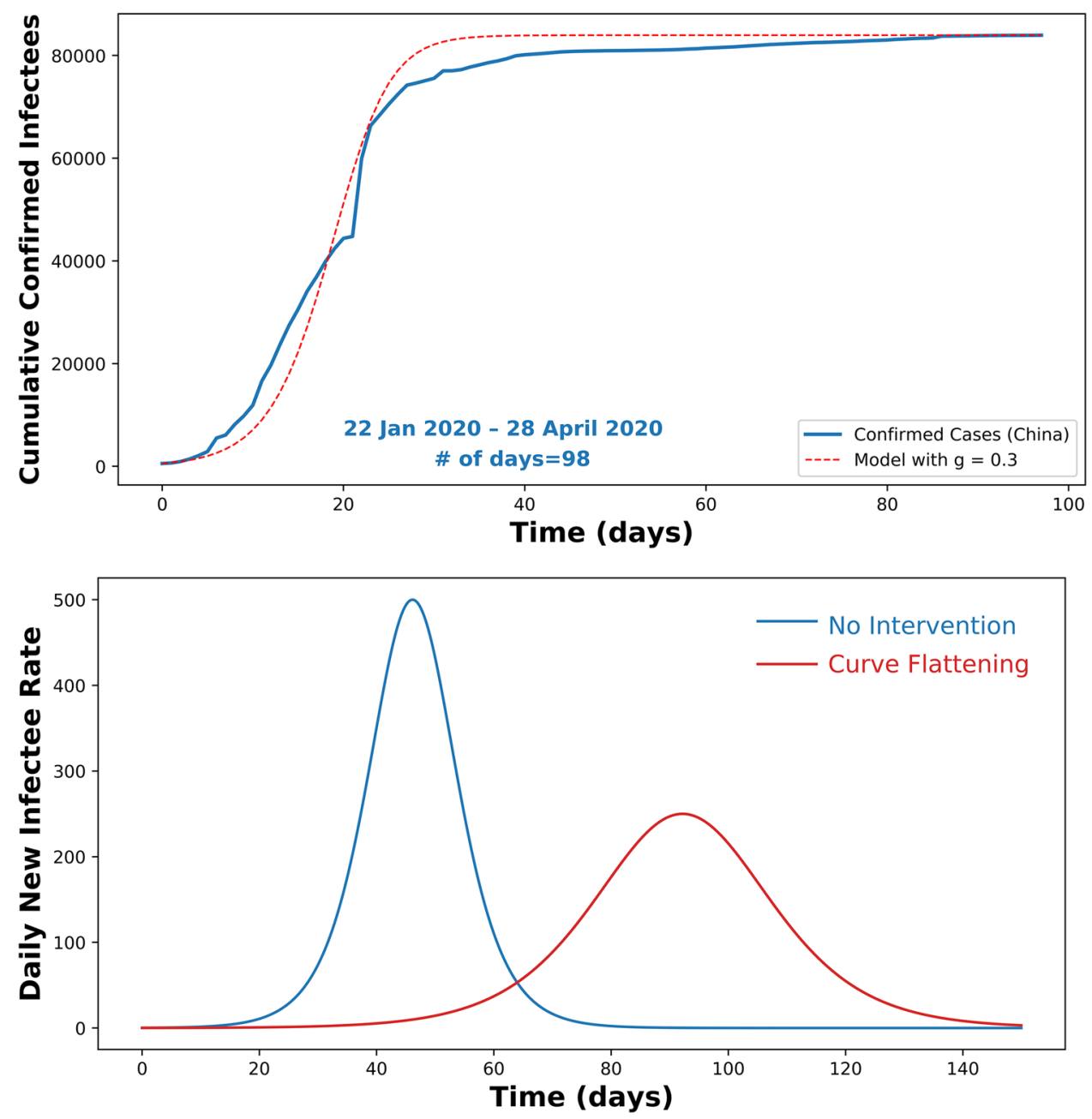

gov/mmwr/volumes/69/wr/mm6915e2.htm?s_cid=mm691 5e2_x) for which a single $R_{\mathrm{o}}$ metric grossly simplifies the reality (for example the U.S., where 20 March, 2 April, 12 April); in these cases we acknowledge this complexity but consider our estimates to best represent available information at the time of writing. $R_{\mathrm{o}}$ values, mitigation dates and $\%$ effectiveness estimates, and projected fatalities are included in the Supplementary Information item 2 accompanying this manuscript.

Infection and cumulative fatality scenarios vary widely and are highly sensitive to small changes in \% mitigation scenarios (e.g. Fig. 1d, CHN_3.9_85_67 vs CHN_3.9_85_67), particularly for countries with higher $R_{\mathrm{o}}$ values. Both estimates are intended for the main purpose of demonstrating how reducing mitigation measures can dramatically influence these projections.

In the case of the U.S., where a lifting of restrictions and re-opening of businesses is being considered, reduction in mitigation measures is likely to sustain higher infection and fatality rates (see USA_3.2_30_70_80 curve) concurrent with peak tornado hazard season in the southeast and central
U.S. (blue curve), overlapping with increasing (and peak) wildfire and heatwave hazards, and potentially overlapping with increasing flood, hurricane, and tropical cyclone hazards. Other COVID-19 related restrictions are likely to compound natural disaster and COVID-19 risks. For example, the U.S. Forest Service has cancelled its planned seasonal burns due to COVID-19 restrictions, and travel restrictions may reduce the likelihood of provision of international support for firefighting. This is explored in more detail in Sect. 6.

In the case of Australia, where strong and increasing social distancing measures were enacted nationally beginning on 23 March, daily confirmed infections are reducing significantly, and the cumulative fatality curve has mostly plateaued (as of 16 April 2020). Infection and fatality rates began to increase in Australia after the cessation of the severe 2019-2020 bushfire season ("Black Summer Fires") in which thousands of Australians were forced to evacuate into communal environments; had COVID-19 emerged only 1-2 months earlier in Australia community transmission risks would have been significantly higher. All of the major 
seasonal hazards are reducing or at low levels; it seems less likely that natural multi-hazard scenarios will concur with COVID-19, although the protracted nature of the latter and possibility of stochastic hazards (e.g. earthquakes and outof-peak season floods) means this is still possible.

In the case of Bangladesh, infection and cumulative fatality rates are currently steeply increasing. Some mitigation measures have been in effect; however, the effectiveness of these is currently unclear. Cumulative fatality projections vary widely; our results suggest sustained $70 \%$ average effectiveness (in the absence of other concurrent disasters or major changes in internal variables) could keep fatalities below 10,000, but weaker mitigation strategies forecast $>500,000$ deaths. Regardless of the mitigation scenarios considered here, sharp increases in infections and deaths are predicted to overlap with the forthcoming tropical cyclone and heatwave peak hazard seasons and may overlap with peaks in monsoonal flood hazard. These aspects are further considered in Sect. 6.

In the case of China, renewed 'secondary spikes' in infections in late March and early April enhance uncertainty in epidemiologic projections. If the average post-peak infection and fatality rate reductions have plateaued, our model suggests $~ 4500$ deaths (CHN_3.9_85). However, if mitigative restrictions are relaxed, and if infection resurgences are sustained and stimulate cascading infections, it is conceivable (albeit unlikely) that cumulative fatalities could exceed 70,000 or more (e.g. CHN_3.9_85_67). In the latter scenario, infection and fatality rates could increase concurrently with increasing flood, heatwave, and hurricane and tropical cyclone hazards, which cause more than 1000 fatalities per year in China on average (Han et al. 2016). China also contains regions with high earthquake hazard. To reduce risks of concurrent and cascading multi-hazards, our analysis indicates that strong and sustained mitigation to reduce COVID-19 infection rates are required.

The COVID-19 pandemic is active and continuously evolving. The time interval over which our forecast models are valid is shorter than the expected duration of this crisis. For example, capturing rapid movement of hot spots through China, Italy, Spain, Turkey, and the United States due to continuously evolving population dynamics and government measures adds an additional layer of complexity, reducing the predictive power of forecasts over longer time periods. In the absence of a vaccine, it is conceivable that the COVID-19 pandemic might last for multiple months or years and its resurgence may occur in waves as in any other previous major pandemic (e.g. Cohn 2008). Adapting resurgence histories of previous COVID-19 like pandemics (e.g. human corona virus $\mathrm{HCoV}-\mathrm{OC} 43$ ) for modelling transmission dynamics, Kissler et al. (2020) suggest that the current pandemic or its waves may last through 2024. This effectively translates into an increase in compound risks associated with COVID-19 pandemic, and therefore, while our preliminary analysis of concurrent compound hazards is useful for the time interval considered, it does not preclude the possibility for future multi-hazard scenarios concurrent with COVID-19 to occur beyond the temporal extent of our analysis.

\section{Multi-hazards concurrent with COVID-19}

\subsection{Croatia Mw 5.3 earthquake}

On 19 March 2020 at midnight, the Croatian government introduced strict measures to counter the spread of COVID19 virus as the number of confirmed cases rose to 105 (Dong et al. 2020). These included, closing of borders, shutting down all non-essential activities such as public events and gatherings and service facilities, and requiring employers to facilitate working-from-home arrangements (https://balka ns.aljazeera.net/vijesti/u-hrvatskoj-na-snagu-stupile-strog e-mjere-zabranjen-prelazak-granica). These strict measures were enforced to promote social-distancing to reduce COVID-19 communal infection risks.

Concurrent with the countrywide partial lockdown, a moment magnitude $(\mathrm{Mw}) 5.3$ earthquake occurred in the northern suburbs of Zagreb, the capital of Croatia with a population of over 800,000 . Prior to this earthquake, Zagreb has been devastated by several moderate earthquakes, the latest of which occurred in 1880 with a magnitude of 6.3 (Kozák and Čermák 2010) that caused damage to about 500 buildings within a $\sim 25 \mathrm{~km}$ radius from the epicentre. Past experiences have shaped earthquake preparedness in Zagreb and approximately $80 \%$ of buildings are built to standards consistent with the earthquake building design codes. However, the Mw 5.3 event and its aftershocks in March 2020 caused significant damage and disruption in the city. There was one fatality and at least 27 people suffered injuries. Electricity, water, and heating were lost in some parts of the city and about 250 houses sustained significant damage. An estimated 59 people required temporary shelters due to loss of dwellings (https://abcnews.go.com/Health/wireStory/after shocks-rattle-croatian-capital-day-strong-quake-69744525).

The Croatian earthquake is not an extreme natural disaster scenario. However, it provides a useful perspective of compound risks. For example, in the immediate aftermath of a natural disaster, measures imposed to ensure socialdistancing may collapse temporarily. Due to the moderate size of the event and relatively localized damage zone, the Croatian government managed to clamp down on partial lockdown measures within about a day by issuing new directives, whereby the natural human behaviour of congregating in numbers and comforting each other in the aftermath of such an event was disrupted. Nonetheless, it is evident that 
the risk of COVID-19 transmission increased in a short-time window immediately following the Zagreb earthquake.

The daily new infectee rate (Fig. 3) shows an apparent increase following the Zagreb earthquake on 22 March 2020 within the COVID-19 incubation time range. Further analysis is needed to ascertain the exact cause of this apparent signal although it is not unreasonable to presume that temporary disruption of social-distancing measures not only in Zagreb but also in other parts of the country in the immediate aftermath of the earthquake might have played a role. Therefore, the importance of acting rapidly and decisively by governing bodies in the immediate aftermath of a natural disaster is highlighted by the Zagreb earthquake. Identifying probable natural disasters and advance preparation might enable enforcing such actions more efficiently and systematically, reducing risks posed by the COVID-19 virus.

\subsection{Tropical Cyclone Harold (TCH)}

TCH originated as a severe meteorologic event in the Pacific Ocean and made landfall in Solomon Islands, Vanuatu, Fiji, and Tonga between 1 April 2020 and 8 April 2020 (https:// public.wmo.int/en/media/news/tropical-cyclone-harold-chall enges-disaster-and-public-health-management), disrupting COVID-19 early intervention made by these communities. It first hit the Solomon Islands as a Category 2 event and rapidly transitioned into a Category 5 event by the time it reached Vanuatu, sustaining high winds of $200 \mathrm{~km} / \mathrm{h}$. Moving further southeast, it traversed Fiji and Tonga as a Category 4 tropical cyclone.

Initial assessments indicate that 59,000 people were affected in Solomon Islands and 27 people are missing at sea to date. In Vanuatu, the northern province Sanma sustained severe damage, where $90 \%$ of the population lost their homes and about $50 \%$ schools and $25 \%$ health centres were damaged. Initial aerial investigations conducted by the National Disaster Management Office of Vanuatu indicate that 159,474 people have been affected with possible 3 deaths (https://ndmo.gov.vu/tropical-cyclone-harold). The damage to houses, evacuation centres, gardens, water systems, health facilities, and schools vary between 50 and 90\% across seven different provinces (https://ndmo.gov.vu/ tropical-cyclone-harold/category/100-01-ndmo-situationreports\#). In Fiji, more than 1500 people have been moved to evacuation centres. The coastal flooding early warning system recently installed under the Coastal Inundation Forecasting Demonstration Project in Fiji recorded storm surge heights between $6.5 \mathrm{~m}$ and $8.5 \mathrm{~m}$ during the passage of TCH, which suggests that damage to life and property might be higher than known at present. Damage in Tonga is less documented but expected to be widespread with damage to homes, water supply, and food crops. TCH provides an example of how disaster response and recovery may impact
COVID-19 measures. For example, Vanuatu has reduced in-country travel restrictions to facilitate humanitarian and relief operations. However, reduced capacity of communication services, disruptions infrastructure lifelines and supply chains, and limited resources are likely to compromise relief efforts and may increase societal vulnerability to COVID-19. Fortunately, these islands have recorded a very low number of COVID-19 confirmed cases to date, and it is yet to be seen if TCH has perturbed this trend.

\subsection{3 Eruption of Anak Krakatau in Indonesia}

Anak Krakatoa garnered much attention after its southwestern flank collapsed in an eruption in December 2018 and generated a tsunami that killed 437 and injured thousands along western Java and Southern Sumatra (Ye et al. 2020). The volcano started a new eruption cycle on 10 April 2020 concurrent with the COVID-19 pandemic. This has remained an active situation to date with constant alerts being disseminated to the public (https://magma.esdm. go.id/v1/vona?page=1) with a Volcano Observatory Notice for Aviation (VONA) alert level assigned as orange (3/4): "Volcano is exhibiting heightened unrest with increased likelihood of eruption with column height below $6000 \mathrm{~m}$ above sea level". To our knowledge, no damage has been reported from this latest eruption cycle. A flank collapse analogous with the December 2018 is very unlikely as the volcano has greatly reduced in aerial extent as a result of that event. However, this highlights in general the high volcanic hazard throughout Indonesia, and the risk of volcanic activity to cause fatalities and population displacements that could impact on current COVID-19 mitigation strategies. Indonesia is still in early stage of the pandemic with only 4839 confirmed cases and 459 deaths; however, the mortality rate of $9.5 \%$ is higher than global average of $6.4 \%$ on 14 April 2020.

\subsection{Tornadoes in the southeastern US}

On 12 and 13 April, cold fronts crossed the southeast of the United States bringing widespread rainfall and embedded mesoscale convective systems (MCSs) with associated strong winds and tornadoes. The MCSs within the larger weather system crossed several states, but Mississippi, Georgia and South Carolina were the worst impacted. The severe weather killed at least 30 people (https://www.nytim es.com/2020/04/13/us/tornado-storm-south.html) across four states and destroyed many more peoples' homes.

The typical immediate emergency response during a tornado outbreak is centred around finding shelter and this is practised by the community in the central and southeast US which has been well drilled in this process through past experience of severe weather. There is obvious potential for 
social distancing to be compromised where large tornado shelters are used, but accurate weather forecasts allowed for planning so that individual families within shelters were instructed to stand apart. Concerns about managing disaster response during the COVID-19 pandemic prompted the American Meteorological Society to draw up a list of guidelines for sheltering from tornadoes during the COVID-19 pandemic (https://www.ametsoc.org/index.cfm/ams/about -ams/ams-statements/statements-of-the-ams-in-force/torna do-sheltering-guidelines-during-the-covid-19-pandemic/). Much of the advice is consistent with standard procedures for severe weather, but additionally people should be sure ahead of time that specific tornado shelters are open.

The US was in the midst of a steep rise in COVID-19 cases and fatalities at the time of this tornado outbreak. It is presently unclear whether this severe weather has compounded the effects of the COVID-19 pandemic in the southeast US.

\section{A simple epidemic phenomenological model with a concurrent event}

\subsection{Method}

To qualitatively understand the effect of an external perturbation such as a natural hazard on the daily COVID-19 infectee rate, we created a simple epidemic model assuming that the cumulative growth of infectees over time follows a logistic differential function [Eq. (1)]. For a holistic analysis, this simple model is appropriate as the distribution of confirmed cumulative COVID-19 cases in countries that have implemented strict counter measures (e.g. China, South Korea, and Australia) can be approximately explained by this model. The exponential growth of COVID-19 cases observed in other countries is an indication of early stage exposure to the disease and that patient distribution is not sustainable over a longer time horizon due to the finiteness of populations and counter measures taken by governments. Therefore, the cumulative distribution of COVID-19 cases can be expected to converge to a model similar to that described by some variation of Eq. (1).

$\frac{d N}{d t}=g\left(1-\frac{N}{N_{\max }}\right) N$

where $N$ is the cumulative number of infectees at any given time, $t$ is time, $N_{\max }$ is the expected maximum number of infectees, and $g$ is the fractional growth of cumulative infectees. Figure 4 compares data from China and the model based on Eq. (1) with $g=0.3, N_{\max }=83,213$ and a time horizon of 83 days, where an approximate value for $g$ is selected based on visual inspection of the fit between data and the model.
Note that the first patient in China was potentially discovered on 10 December 2019 and data for the period from that day to 22 January 2020 (start date given in the figure) is not reliably recorded (https://www.wsj.com/articles/how-it-all-start ed-chinas-early-coronavirus-missteps-11583508932).

Rather than analysing cumulative infectee numbers, we focus on the effect on the "flattened" daily new infectee rate following an external perturbation (e.g. a natural disaster) as it is the behaviour of this curve that is being used to design COVID-19 counter measures ("curve flattening" shown in Fig. 4 bottom panel). We make several assumptions to construct our simple models:

(1) In the immediate aftermath of an extreme natural disaster, it is reasonable to assume that measures taken to contain the spread of COVID-19 collapse in the area directly affected by the event and the control over spreading rate is lost, resulting a spike in infectees. In this case, we assume that the spreading rate increases to the background value that existed prior to imposing "curve flattening" measures.

(2) Governments re-establish social-distancing measures fully over a finite time horizon $\left(P_{\text {days }}\right)$ following the external perturbation, which means that the flattened spreading rate that existed prior to the external perturbation will take effect beyond $P_{\text {days }}$. In the interim period (i.e. within $P_{\text {days }}$ ), it is highly likely that governments will take partial measures that will reduce the spreading rate as was seen for the earthquake in Croatia. Also, compliance of citizens to these partial measures can be expected although it may depend on the severity of the event and the socio-political profiles of countries. Thus, we model this effect by linearly reducing the spreading rate from the background value to the flattened value in the interim period. We test several reasonable time horizons to understand their effect on the flattened daily new infectee rate curve. Depending on the nature of the external perturbation, different scenarios may play out. For instance, in the event of a flood, a population may get displaced and scattered from days to months (Sastry 2009) or it may be that populations get displaced but not scattered as in the case of an earthquake (Akbari et al 2004; Asokan and Vanitha 2017). These different scenarios will have an effect on the spreading rate. Describing the spreading rate quantitatively for different scenarios is not the focus of our modelling. Instead, we model the general behaviour of the "flattened curve" in the event of an external perturbation subjected to above (1).

(3) The COVID-19 incubation time period (the time between exposure to the virus and emergence of symptoms) is five days, consistent with the median incubation time published by WHO (https://www.who.int/ 
208

Environment Systems and Decisions (2020) 40:199-215
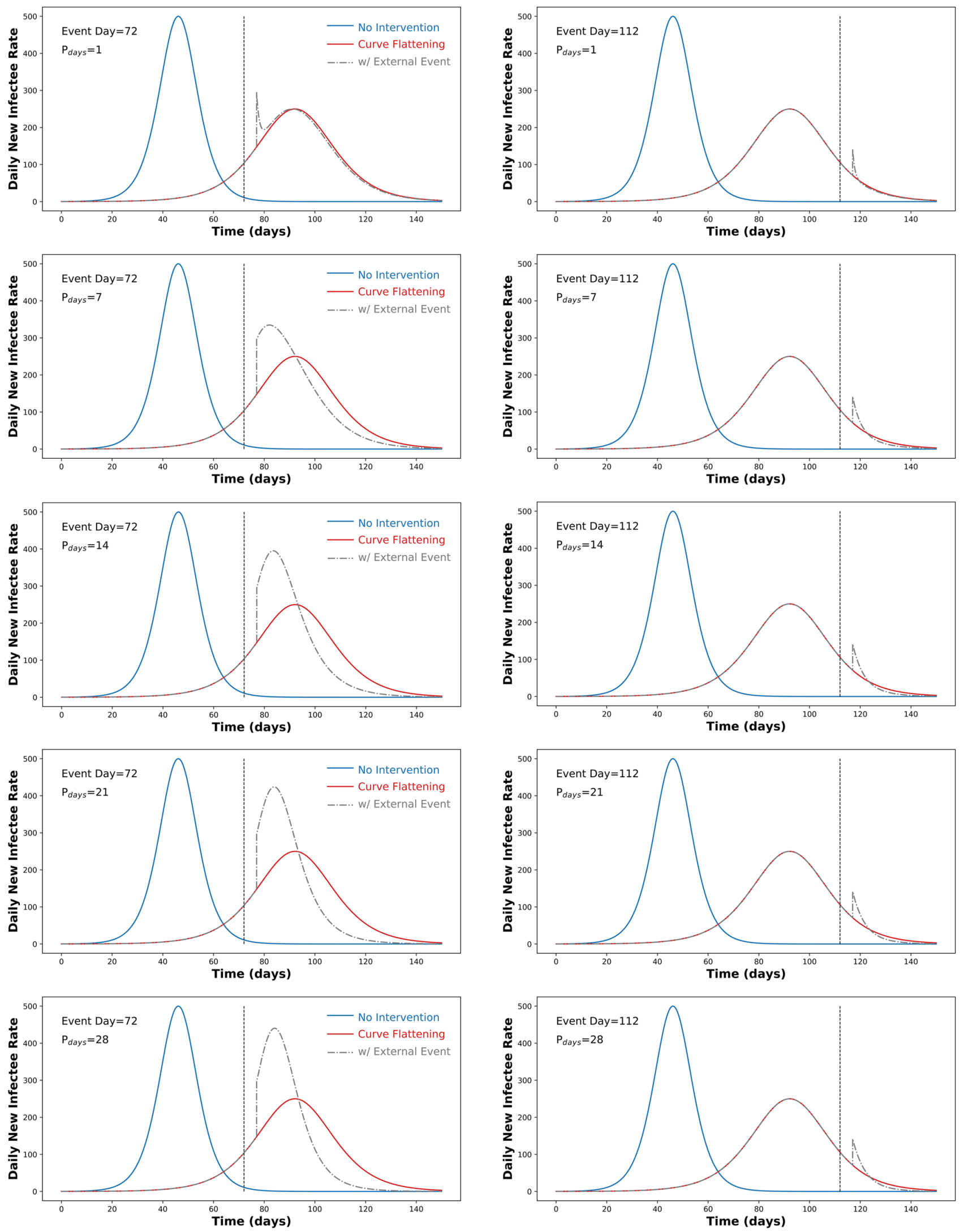

Springer 
4Fig. 5 The daily new infectee rate with a concurrent event (e.g. a natural disaster). Red and blue curves are same as those given in Fig. 4 (bottom panel) and the grey dash-dot curve is the flattened curve perturbed by a concurrent event. The vertical dashed black line is the event day. The left panel shows the effect on the flattened curve for an event occurrence in the pre-peak period, whereas the right panel is for an event occurrence in the post-peak period. Each row represents a given $P_{\text {day }}$, the number of days a government takes to fully re-establish COVID-19 counter measures following the concurrent event. Pre-peak events increase the daily new infectee rate more than post-peak events. Also, the longer the governments take to reestablish strict COVID-19 counter measures, the higher the daily new infectee rate

news-room/q-a-detail/q-a-coronaviruses). This means that no new cases will be found within the first five days following an event. This simplifies the "ground truth" somewhat, as according to WHO, incubation time range varies between one and fourteen days.

In our models, we set $\mathrm{Nmax}=10,000$, a background spreading rate $\left(g_{\mathrm{b}}\right)$ of 0.2 , a flattened spreading rate $\left(g_{\mathrm{f}}\right)$ of 0.1 , and a time horizon of 150 days. We test the perturbation to the flattened curve with $P_{\text {days }}=1,7,14,21$, and 28 days.

\subsection{Results}

Figure 5 shows the results of modelling the flattened daily new infectee rate after introducing a concurrent event with $P_{\text {days }}=1,7,14,21$, and 28 days. For each $P_{\text {days }}$, we tested two scenarios, where we introduce external perturbations at 72 (left panels) and 112 days (right panels) from the start date of the flatten curve. These two time points are located symmetrically on either side of the peak of the flattened curve (day 92), and thus, provide qualitative insights into demands on the health services depending on the event occurrence relative to the peak.

Our results provide two main insights: (1) A concurrent event occurring prior to reaching the peak of the flattened curve increases the new infectee rate more in the aftermath of a concurrent event than if it were to occur at a post-peak time. This translates into increased demand on health services in the pre-peak period than in the post-peak period. In some instances, pre-peak concurrent events increase curveflattened peak infection rates to levels approaching unmitigated peaks. (2) The number of days a government takes to re-establish COVID-19 spreading control measures $\left(P_{\text {days }}\right)$ is a critical factor that determines the level of demand placed on health services. That is, the longer it takes for a government to re-establish control measures, the higher the demand on the health services particularly in the pre-peak period.

These results based on our simple model emphasize two main policy recommendations that governments could consider. First, measures must be enforced as early as possible to flatten the daily new infectee rate curve to minimize risks of temporally-overlapping COVID-19 infection rate increases with concurrent disasters. This reduction of risk of a natural disaster occurring in the pre-peak period could reduce demand on health services. Second, contingency plans must be devised with a focus on re-establishing COVID-19 counter measures as fast as possible in the wake of an event. This would involve identifying possible natural disasters, their magnitude, timing (for example seasonal events), and regional dependencies.

Following our example, more sophisticated models can be built to incorporate infectious disease dynamics in the wake of a concurrent event. For example, we have only considered the infected component in this instance, whereas a standard epidemiological compartmental model will incorporate susceptible and recovered components in addition to the infected component (Kermack and McKendrick 1927) enabling the mapping of dynamic interactions between different population groups. Prediction capabilities can be further improved with even more complex models, where the underlying assumption of a well-mixed population is relaxed, and structured populations are used to reflect variable dynamics among different groups of population (e.g. Inaba and Nishiura 2008). For real time applications, however, more work will be needed to reduce uncertainties in parameters that capture the spatiotemporal characteristics of spreading of a disease (e.g. $R_{0}$, Ridenhour et al. 2014).

\section{Discussion}

\subsection{Concurrent multi-hazard cascades during the COVID-19 crisis}

The combined epidemiological COVID-19 forecasts and seasonal hazard risk plots in Fig. 1 illustrate the different extreme weather hazards that countries will likely need to manage during different stages of the pandemic. While we have not modelled stochastic hazards such as earthquakes, they contribute a non-negligible to high hazard with regional variability for all the countries considered. Volcanic hazard is highly regionalized and not further discussed, but is highly relevant in some locations.

\subsubsection{Australia}

In Australia, summer 2019/20 saw substantial natural hazards including major heatwaves that brought record high temperatures to populated areas including Canberra and western Sydney, severe bushfires that swept through an unprecedented area of the continent (Boer et al. 2020) and continuing drought that has devastated farming areas, diminished water supplies and primed the Australian forests for bushfire (King et al. 2020). Australia's “Black Summer” also 
saw millions of people experience very poor air quality for several days at a time as smoke from the fires blanketed Sydney, Canberra and Melbourne on several occasions. The bushfires, which resulted in 33 fatalities, led to mass evacuations from vulnerable areas and people sheltering on crowded beaches in Mallacoota, Victoria amongst other places.

The "Black Summer" came only months before the COVID-19 pandemic began and as Australia approaches winter the risks of severe weather related to heatwaves, bushfires, tropical cyclones and hailstorms is reduced. While there are still natural hazard risks in Australian winter, notably related to floods and extratropical cyclones, the overall rate of meteorological hazards is lower than in summer. In that sense Australia is fortunate to have not experienced major natural hazards coincident with the COVID-9 pandemic, and it is less likely to do so than Northern Hemisphere countries over the coming months. Note, that there are non-natural hazards that could also occur during winter that could exacerbate the effects of COVID-19 in Australia such as seasonal flu.

\subsubsection{The United States}

In the US, we have already highlighted the tornado outbreak of 12 and 13 April as occurring during the COVID-19 pandemic. The US experiences its seasonal peak in tornado probability in May, so there are likely to be further severe storms around this time. During boreal summer, the US often experiences other natural hazards including heatwaves and hurricanes. While these extremes both have devastating impacts their interaction with the ongoing COVID-19 pandemic will likely differ. Heatwaves tend to exacerbate preexisting health conditions. This would place an additional burden on a healthcare system that may also be stretched due to COVID-19. In contrast, hurricanes tend to damage infrastructure, and, like tornadoes, people evacuate and shelter, often travelling interstate or sheltering with many other people in large buildings. Such a response to a hurricane in summer 2020 would not abide by social distancing protocols and could aid the spread of the virus. Alternate plans should be considered. Both heatwaves and hurricanes affect larger areas than tornadoes and have the potential to strain emergency response systems already managing the COVID-19 pandemic.

\subsubsection{South Asia}

South Asian countries with some of the highest population densities (https://neo.sci.gsfc.nasa.gov/view.php?datas etId=SEDAC_POP) are exposed to compound risks from COVID-19 pandemic and extreme weather events such as severe floods as the region enters the wet season from May to October. For instance, 1110 people died and nearly 14 million were affected in the floods of June 2007 in Bangladesh (Dewan 2015). In addition, Northern Pakistan and India, Nepal, and Bhutan are located along the Himalayan main frontal thrust capable of producing large $\mathrm{Mw}>7.0$ earthquakes (Lavé et al. 2005). The devastation caused by the $2015 \mathrm{Mw} 7.8$ Gorkha earthquake that occurred in Nepal exemplifies the exposure of this region to extreme geologic hazards. This particular event killed 8,790 people, injured 22,304 and affected another 8 million people and damaged 755,549 buildings (Gautam 2017). It is evident from these statistics that solitary extreme natural hazards in this region have the potential to affect large numbers of people and displace them. In particular, displacement in large numbers during severe natural events is mainly attributable to the poor quality of dwellings and infrastructure. This in turn is detrimental to measures enforced to counter the spread of COVID-19, foremost of which is social distancing. In the event of natural hazards, these measures are highly likely to disintegrate completely, substantially increasing the risk of COVID-19 infections.

\subsubsection{Other}

While we have qualitatively aggregated these hazards on an domestic scale, the countries considered herein (and many other countries with high natural disaster risk including Japan, The Philippines, Iran, Turkey, and many central America and Pacific island nations) have strong regional variations in hazard, exposure, and vulnerability that are superimposed on spatiotemporal variabilities in COVID-19 risks. It is well beyond the scope of this article to consider these regional variations. However, we provide one example, from the U.S. state of Texas (Fig. 6). Currently Texas has implemented two of four potential social distancing measures but has a climbing rate of COVID-19 hospitalizations and deaths that are collectively increasing demand on resources (Fig. 6). Projected peaks in fatality rate and hospital demand overlap with the seasonal peak in tornado hazard (Long et al. 2018). Upper bounds (95\% confidence) on projected ICU resource capacity currently approach ICU bed availability; if tornadoes increase ICU demand (by increasing critical care injuries associated with the tornado and/or COVID-19 infectees) or reduce capacity (by power outages and infrastructure damage) then it is conceivable that resource limits could be approached.

\subsection{Implications for humanitarian response}

In 2020 it is estimated that 167 million people across 55 countries will require humanitarian assistance (OCHA 2019). With ongoing global economic uncertainty (IMF 2020), it is unclear what impact the COVID-19 pandemic 


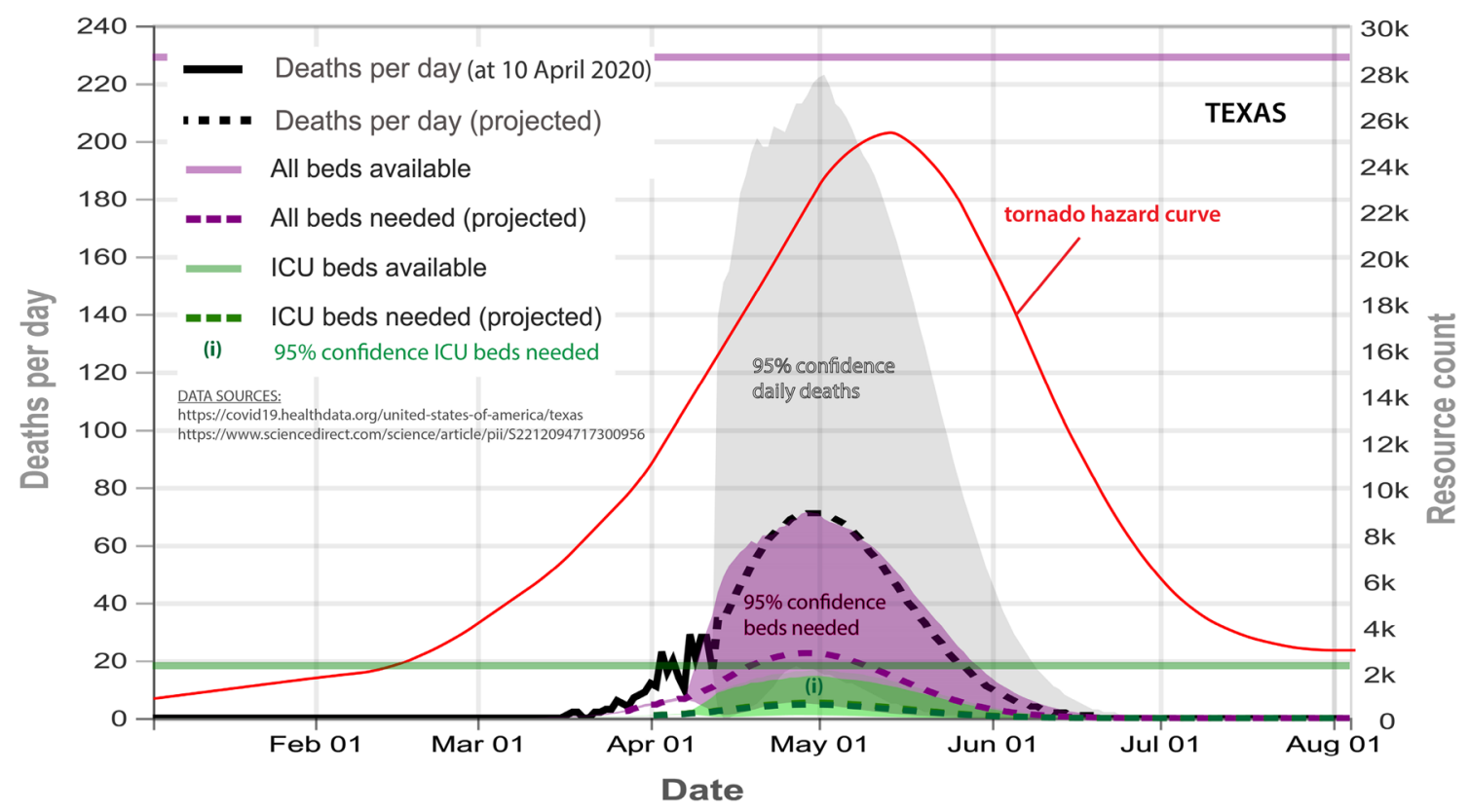

Fig. 6 COVID-19 daily deaths, hospital bed usage and capacity, and future projections plotted against the tornado seasonal hazard curve. The concurrency of increased COVID-19 and tornado hazards define heightened risk of a multi-hazard scenario that could greatly increase

will have on humanitarian financing and resource mobilization. In the event that a crisis exceeds the coping capacity of a host country, a funding or resourcing gap resulting from COVID-19 would severely impair the government's ability to deliver critical humanitarian aid and to scale-up response efforts to meet the needs of the affected population.

For many countries, a hazard response beyond the coping capacity of the government will trigger a Level 3 (L3) InterAgency Standing Committee (IASC) Humanitarian SystemWide Scale-Up (IASC 2018) involving one or more clusters/ sectors (i.e. Water Sanitation and Hygiene (WASH), Health, Protection, Logistics, Shelter) to coordinate response efforts. Responding to a L3 multi-hazard situation during COVID19 will require additional resources and rely more heavily on integrated programming and inter-sectorial coordination incorporating competing priorities from different clusters/ sectors.

Where countries have an existing Humanitarian Response Plan (HRP), or contingency planning simulations have been carried out such as the 2019 "Bangladesh contingency plan for earthquake response in major urban centres" (HCTT 2019), response plans will need to be revised, to account for the increased risk of disease transmission and additional limitations and access considerations imposed by COVID-19 during response and recovery operations.

Where an IASC system-wide L3 emergency response is triggered, such as a major earthquake on a similar scale to the 2015 Gorkha Earthquake, global humanitarian response demand on hospital resources and increase COVID-19 exposure risks in instances where existing tornado evacuation procedures such as communal clustering into shelters are undertaken

mechanisms may be limited in their ability to rapidly mobilize international surge capacity (including humanitarian staff and volunteers) and resources typically relied on for large-scale humanitarian response. International military deployments may also be limited due to an increasing focus on domestic priorities. As a result, response efforts will likely need to become much more localized, with a focus on improving remote coordination and support for local responders. Movement restrictions will make it increasingly difficult for remote and isolated populations to seek medical services and assistance (OCHA 2020) and specialized services such as psychosocial support will increasingly need to be delivered through remote systems, as already observed during the recent Croatia Earthquake Response (IFRC, 2020). Multi-hazard risk profiles in these circumstances will need to include an array of often compounding vulnerabilities, such as the risk to elderly populations and the elevated risk of sexual and gender-based violence.

Logistics supply chains have already been severely compromised by COVID-19, with a disruption of critical supply chains due to border closures, import/export restrictions, and access restrictions (OCHA 2020). This will influence the way humanitarian programming can be implemented. Stimulation of local markets (where they still exist) through cash and voucher assistance (CVA) programming, improved engagement with the private sector, and utilization of local industry and resources and will likely play an increasing role in strategies for recovery. 
A multi-hazard situation in an already compounded and protracted or 'complex' emergency is of particular concern. These include densely populated camp-like situations with a high risk of natural hazard, such as the Bangladesh Rohingya Refugee Response. As of December 2019, some 810,000 Rohingya refugees live in 34 congested camps at high risk of flooding, landslides and seasonal cyclones, and are reliant on humanitarian aid to meet basic needs (OCHA 2019). The added complication of COVID-19 containment measures into this already protracted crisis will put populations at significant risk of loss of life and will cause unprecedented complexity for humanitarian response efforts in the event of a natural hazard. Dense settlements, with a high population density will need to carefully consider social and physical distancing measures in humanitarian programming. This will limit the types of assistance (emergency centres, camps, emergency shelter, cash distributions, rental assistance, etc.) that can be delivered and the implementation modalities that can be used without increasing risk of transmission, and thereby compromising efforts to contain COVID- 19.

It is essential that humanitarian response remains proportionate, appropriate and relevant to the emergency, while still being timely and effective (Sphere 2020). Humanitarian response should avoid exposing populations to further harm, and it is critical that preparedness plans pre-emptively assess and evaluate the compounding risks posed by COVID-19 in multi-hazard situations. A tiered resilience approach that concurrently integrates resilience indices, visualization tools, and modelling methods from multiple agencies, organizations, and researchers could assist in reconciling analytical complexity with stakeholder (humanitarian organizations and beneficiaries) needs and resources available for creating actionable recommendations to enhance resilience (Linkov et al. 2018).

\section{Conclusions and recommendations}

Our analysis suggests that without good planning there is an increased risk of compounding impacts originating from natural hazard event(s) during the COVID-19 pandemic. This could include both the effects of the natural disaster being worse than they would otherwise be, and additional spread of COVID-19. Here we make several recommendations we believe could alleviate some of the worst effects of natural hazards during the pandemic:

\subsection{Make extensive use of pandemic and natural disaster hybrid models}

The compounding effect of seasonal natural hazards (e.g. floods, cyclones) on the COVID-19 pandemic is largely a foreseeable problem and plans developed ahead of time could prevent some of the worst potential impacts from occurring. These plans can be based on modelling similar to that shown in this paper and we encourage emergency management agencies to consider use of these hybrid models to build response plans. COVID-19 epidemiological models may be highly sensitive to natural disasters, and thus inclusion of seasonal and / or stochastic events might better enable worst-case scenarios to be considered. This may be particularly important considering (a) the effect on infectee rate of the timing of a concurrent event relative to the peak of the infectee rate curve as demonstrated in this study (Fig. 5); (b) the uncertainty in intensity and duration with which COVID-19 counter measures must be implemented for them to be effective.

\subsection{Make extensive use of weather forecasting and seasonal prediction models}

Where possible, use of prediction models may help agencies ramp up emergency planning procedures days and weeks before meteorological extremes occur. For example, seasonal prediction allows advance planning for the possibility of specific weather extremes and this should be undertaken to prevent some of the worst impacts of such events. There is already an indication that the 2020 Atlantic hurricane season will be unusually active (e.g. https://engr.source.colostate. edu/csu-researchers-predicting-active-2020-atlantic-hurri cane-season/), so planning for major land-falling hurricanes in the US over heavily populated cities during the COVID19 pandemic could be beneficial. In particular, developing alternate response plans and communicating these well in advance should prepare people for the most suitable actions to take that keep them safe from the hazard while also adhering to social distancing, could help in preventing a major disaster. Even on the timescale of numerical weather prediction, the response to the 12-13 April tornado outbreak demonstrates that several days may be enough to prepare for well-forecast small-scale extreme weather events.

\subsection{Re-design policy responses to different natural hazards}

It is likely that hazard mitigation measures for worst-case scenarios of expected natural disasters, seasonal or stochastic, are already in place for many countries and regions (e.g. Hurricanes in the US, Floods in Bangladesh, earthquakes in Nepal). However, these plans do not account for the existing COVID-19 crisis that requires social-distancing as the primary counter measure. Thus, incorporating effects of natural hazards in epidemiological models can guide modifications required in existing natural hazard mitigation plans. The compound risks associated with stochastic natural disasters (e.g. earthquake, volcanic eruptions) can potentially 
be mitigated by modifying existing hazard mitigation plans. Specific suggestions include establishing strategies for decongestion of densely populated spontaneous camps and settlements, introducing clear physical distancing protocols for distribution of essential assistance, increasing space allocations for vulnerable populations in shelters to reduce the risk of COVID-19 transmission, and the use of more emergency shelter locations with fewer people so that some semblance of social distancing may be achieved even in the aftermath of a hurricane or earthquake. Large-scale availability of personal protective equipment (PPE) to emergency responders would also help prevent the spread of infection.

\subsection{Support agencies working in developing regions to manage relief efforts}

Given the disproportionate impacts of many prior pandemic and natural hazards on the developing world, plans to equip developing countries and NGOs in preparing for and responding to natural hazards during the COVID-19 pandemic would help limit the impacts of such disasters.

As our simple epidemiology models show, spikes in daily new infectee rates are a likely scenario in the wake of a natural disaster. The magnitude and duration of these spikes could in principle be controlled by policy decisions (described above). Thus, disaster planning strategies and resourcing, such as the introduction of remote coordination platforms, the localisation of response efforts and resources, availability of evacuation centres with capacity for social distancing, potential mobility of humanitarian actors, volunteers and medical staff that could respond to natural disasters in COVID-affected regions, and the availability of personal protective equipment and medical equipment (e.g. respirators) must be designed in combination with above (ii). Countering challenging conditions associated with natural hazards (limited road access, lack of communication etc.) must be considered in upholding COVID-19 social-distancing measures.

We offer these recommendations in the hope that they may be used to prevent some of the worst-impact scenarios of coincident natural hazard occurrences with the ongoing COVID-19 outbreak. These recommendations support the independently-derived strategic disaster risk reduction recommendations proposed by Djalante et al. (2020): (i) Strengthen knowledge and science provision in understanding disaster and health-related emergency risks, (ii) Mobilize existing disaster risk governance structure to manage disaster risk and potential health-emergencies, (iii) Utilize existing disaster coordination mechanisms at regional level to inform epidemic response, (iv) Understand COVID-19 economic implications and resilience, (v) Prepare inclusive early recovery plans, and (vi) Strengthen community-level preparedness and response. Urgent sharing of scientific information (models, methods), particularly with developing countries, is important because many of these countries may lack capacity to generate knowledge rapidly to improve resilience against foreseeable compound risks.

Our recommendations are framed around the ideas of building resilience to natural hazard risks such that their impacts are reduced in the era of COVID-19. We note that the concept of increasing resilience to mitigate impacts of extreme events is not novel (Bostik et al. 2018; Linkov et al. 2018); however, we hope that our suggested actions will build on those provided previously and will be used to reduce risks from natural hazards during the COVID-19 outbreak. Our use of plausible scenarios could stimulate production of resilience analyses that incorporate uncertainty and complex dynamics of physical and human/social factors across multiple spatial and temporal scales (e.g. Bostik et al. 2018).

Acknowledgements Emma Hudson-Doyle, Deborah Hutchinson, and Igor Linkov provided valuable reviews of this work. A.D.K. was funded by the Australian Research Council (DE180100638).

\section{Compliance with ethical standards}

Conflict of interest The authors declare that they have no conflict of interest.

\section{References}

Asokan GV, Vanitha A (2017) Disaster response under One Health in the aftermath of Nepal earthquake, 2015. J Epidemiol Glob Health 7(1):91-96. https://doi.org/10.1016/j.jegh.2016.03.001

Akbari ME, Farshad AA, Asadi-Lari M (2004) The devastation of Bam: an overview of health issues 1 month after the earthquake. Public Health 118:403-408. https://doi.org/10.1016/j. puhe.2004.05.010

Benson C, Clay E (2002) Bangladesh: disasters and public finance, working paper series 6, Disaster Management Facility. The World Bank, Washington DC

Boer MM, de Dios VR, Bradstock RA (2020) Unprecedented burn area of Australian mega forest fires. Nat Clim Change 10(3):171-172

Bostick TP et al (2018) Resilience science, policy and investment for civil infrastructure. Reliabil Eng Syst Saf 175:19-23

Brooks HE, Kay MP (2003) Climatological estimates of local daily tornado probability for the United States. Weather Forcast 18:624-640

Campanella N (1999) Infectious diseases and natural disasters: the effects of hurricane mitch over Villanueva Municipal Area, Nicaragua. Public Health Rev 27(4):311-319

Chowdhury R (2000) An assessment of flood forecasting in Bangladesh: the experience of the 1998 flood. Nat Hazards 22:139-163

Cohn SK Jr (2008) 4 Epidemiology of the black death and successive waves of plague. Med Hist Suppl 27:74-100

Colwell RR, Machlis GE (2019) Science during crisis: best practices, research needs, and policy priorities. American Academy of Arts and Sciences, Cambridge, $\mathrm{p} 22$

Dewan TH (2015) Societal impacts and vulnerability to floods in Bangladesh and Nepal. Weather Clim Extrem 7:36-42. https:// doi.org/10.1016/j.wace.2014.11.001 
Djalante R, Shaw R, DeWit A (2020) Building resilience against biological hazards and pandemics: COVID-19 and its implications for the Sendai Framework. Prog Disaster Sci 1:100080

Dong E, Du H, Gardner L (2020) AN interactive web-based dashboard to track COVID-19 in real time. Lancet Infect Dis. https ://doi.org/10.1016/S1473-3099(20)30120-1

Doocy S, Rofi A, Moodie C, Spring E, Bradley S, Burnham G, Robinson C (2007) Tsunami mortality in Aceh Province, Indonesia. Bull World Health Organ 85(2):273-278. https://doi. org/10.2471/BLT.06.033308

Doocy S, Cherewick M, Kirsch T (2013) Mortality following the Haitian earthquake of 2010: a stratified cluster survey. Popul Health Metr. https://doi.org/10.1186/1478-7954-11-5

Dove MR, Khan MH (1995) Competing constructions of calamity: The April 1991 Bangladesh cyclone. Popul Environ 16(5):445-471

Filippelli G (2020) Geohealth: science's first responders. EOS. https:// doi.org/10.1029/2020EO142663

Gautam D (2017) Unearthed lessons of 25 April 2015 Gorkha earthquake (Mw 7.8): geotechnical earthquake engineering perspectives. Geomatics 8(2):1358-1382. https://doi.org/10.1080/19475 705.2017.1337653

Harrison CG, Williams PR (2016) A systems approach to natural disaster resilience. Simul Model Pract Theory 65:11-31

Han W, Liang C, Jiang B, Ma W, Zhang Y (2016) Major natural disasters in China, 1985-2014: occurrence and damages. Int J Environ Res Public Health 13(11):1118

HCTT (2019) Contingency plan for earthquake response in major urban centres-Bangladesh. https://www.humanitarianresponse.info/ sites/www.humanitarianresponse.info/files/2019/07/HCTT_Conti ngency-plan_L3-Earthquake.pdf

Hosseini KA, Hosseini M, Jafari MK, Hosseinioon S (2009) Recognition of vulnerable urban fabrics in earthquake zones: a case study of the Tehran metropolitan area. J Seismol Earthq Eng 10(4):175-187

IASC (2018) Protocol 1. Humanitarian system-wide scale-up activation: definition and procedures. https://interagencystandingc ommittee.org/iasc-transformative-agenda

IFRC (2020) Emergency plan of action (EPoA). Croatia: earthquake. https://reliefweb.int/sites/reliefweb.int/files/resources/MDRHR 003do.pdf

IMF (2020) World economic outlook, April 2020. Chapter 1: the great lockdown. https://www.imf.org/en/Publications/WEO/Issue s/2020/04/14/weo-april-2020. Accessed 15 April 2020

Inaba H, Nishiura H (2008) The state-reproduction number for a multistate class age structured epidemic system and its application to the asymptomatic transmission model. Math Biosci 216(1):77-89

Kermack WO, McKendrick AG (1927) A contribution to the mathematical theory of epidemics. Proc R Soc Math Phys Eng Sci 115(772):700-721

Khalil GMd (1993) The catastrophic cyclone of April 1991: its impact on the economy of Bangladesh. Nat Hazards 8:263-281

Khazai B, Anhorn J, Girard T, Brink S, Daniell J, Kunz-plapp T (2015) Shelter response and vulnerability of displaced populations in the April 25, 2015 Nepal Earthquake. https://www.cedim.kit.edu/ download/CEDIM_FDA_NepalEarthquake_Report2Shelter.pdf

King AD, Pitman AJ, Henley BJ, Ukkola AM, Brown JR (2020) The role of climate variability in Australian drought. Nat Clim Change 10(3):177-179

Kouadio IK, Aljunid S, Kamigaki T, Hammad K, Oshitani H (2012) Infectious diseases following natural disasters: prevention and control measures. Expert Rev Anti-infect Therapy 10(1):95-104. https://doi.org/10.1586/eri.11.155

Kozák J, Čermák V (2010) Zagreb (Agram) earthquake, Croatia, 1880. The illustrated history of natural disasters. Springer, Dordrecht, pp 151-153
Lancet (2020) Redefining vulnerability in the era of COVID-19. Lancet 395(10230): 1089

Landsea CW (1993) A climatology of intense (or major) atlantic hurricanes. Mon Weather Rev. https://doi.org/10.1175/15200493(1993)121\%3c1703:ACOIMA\%3e2.0.CO;2

Lavé J, Yule D, Sapkota S, Basant K, Madden C, Attal M, Pandey R (2005) Evidence for a great medieval earthquake ( 1100 A.D.) in the central Himalayas, Nepal. Science 307(5713):1302-1305. https://doi.org/10.1126/science.1104804

Linkov I et al (2018) Tiered approach to resilience assessment. Risk Anal 38(9):1772-1780

Long JA, Stoy PC, Gerken T (2018) Tornado seasonality in the southeastern United States. Weather Clim Extrem 20:81-91. https://doi. org/10.1016/j.wace.2018.03.002

Marin M, Nguyen HQ, Langidrik JR, Edwards R, Briand K, Papania MJ et al (2006) Measles transmission and vaccine effectiveness during a large outbreak on a densely populated island: implications for vaccination policy. Clin Infect Dis 42:315-319. https:// doi.org/10.1086/498902

Martha TR, Roy P, Mazumdar R, Govindharaj KB, Kumar KV (2017) Spatial characteristics of landslides triggered by the $2015 \mathrm{M}_{\mathrm{w}} 7.8$ (Gorkha) and $\mathrm{M}_{\mathrm{w}} 7.3$ (Dolakha) earthquakes in Nepal. Landslides 14:697-704. https://doi.org/10.1007/s10346-016-0763-x

McMahon MM (2007) Disasters and poverty. Disaster Manage Response 5(4):95-97. https://doi.org/10.1016/j.dmr.2007.09.001

Medina-Ramón M, Zanobetti A, Cavanagh DP, Schwartz J (2006) Extreme temperatures and mortality: assessing effect modification by personal characteristics and specific cause of death in a multi-city case-only analysis. Environ Health Perspect 114(9):1331-1336

Mirza MMQ (2002) Global warming and changes in the probability of occurrence of floods in Bangladesh and implications. Global Env Change 12:127-138

Mushtaque A, Chowdhury R, Bhuyia AU, Choudhury AY, Sen R (1993) The Bangladesh cyclone of 1991: why so many people died. Disasters 17(4):338-351

Nissan H, Burkart K, Coughlan de Perez E, Van Aalst M, Mason S (2017) Defining and predicting heat waves in Bangladesh. J Appl Meteorol Climatol 56(10):2653-2670. https://doi.org/10.1175/ JAMC-D-17-0035.1

Normile D (2020) "Suppress and lift": Hong Kong and Singapore say they have a coronavirus strategy that works. Science. https://doi. org/10.1126/science.abc1963

OCHA (2019) Global humanitarian overview 2020. https://www.unoch a.org/global-humanitarian-overview-2020

OCHA (2020) Global humanitarian response plan COVID-19. https:// www.unocha.org/sites/unocha/files/Global-Humanitarian-Respo nse-Plan-COVID-19.pdf

Orata FD, Keim PS, Boucher Y (2014) The 2010 cholera outbreak in Haiti: how science solved a controversy. PLoS Pathog 10(4): 00003967

Quigley M, Saunders W, Massey C, Van Dissen R, Villamor P, Jack H, Litchfield N (2020) The utility of earth science information in post-earthquake land-use decision-making: the 2010-2011 Canterbury earthquake sequence, New Zealand. Natural Hazards and Earth System Sciences. https://www.nat-hazards-earth-syst-scidiscuss.net/nhess-2020-83/

Quigley M, Duffy B (2020) Effects of earthquakes on flood hazards: a case study from Christchurch, New Zealand. Geosciences 10:114. https://doi.org/10.3390/geosciences10030114

Rahman MM, Goel NK, Arya DS (2013) Study of early flood warning dissemination system in Bangladesh. J Flood Risk Manage 6:290-301. https://doi.org/10.1111/jfr3.12012

Ridenhour B, Kowalik JM, Shay DK (2014) Unravelling $R_{0}$ : considerations for public health applications. Am J Public Health 104(2):e32-e41. https://doi.org/10.2105/AJPH.2013.301704 
Ritchie H, Roser M (2020). Natural disasters. Published online at OurWorldInData.org, https://ourworldindata.org/natural-disasters. Accessed 14 April 2020

Roback K, Clark MK, West AJ, Zekkos D, Li G, Gallen SF, Chamlagain D, Godt JW (2018) The size, distribution, and mobility of landslides caused by the 2015 Mw7.8 Gorkha earthquake, Nepal. Geomorphology 301:121-138. https://doi.org/10.1016/j.geomo rph.2017.01.030

Sastry N (2009) Displaced new orleans residents in the aftermath of Hurricane Katrina: results from a pilot survey. Organ Environ 22(4):395-409. https://doi.org/10.1177/1086026609347183

Sheridan SC, Kalkstein AJ (2010) Seasonal variability in heat-related mortality across the United States. Nat Hazards 55(2):291-305. https://doi.org/10.1007/s11069-010-9526-5

Sherman A, Shapiro I (2005) Essential facts about the victims of Hurricane Katrina, Center on Budget and Policy Priorities. https:// www.cbpp.org/sites/default/files/atoms/files/9-19-05pov.pdf. Accessed 15 April 2020

Siddique AK, Baqui AH, Eusof A, Zaman K (1991) 1988 floods in Bangladesh: pattern of illness and causes of death. J Diarrhoeal Dis Res 9(4):310-314

Simonovic SP (2011) Systems approach to management of disasters: methods and applications. Wiley, Hoboken, p 308

Sphere (2020) Applying humanitarian standards to fight COVID-10. www.spherestandards.org

Stucchi M, Meletti C, Montaldo V, Crowley H, Calvi GM, Boschi E (2011) Seismic hazard assessment (2003-2009) for the Italian building code. Bull Seismol Soc Am 101(4):1885-1911
Surmieda MR, Lopez JM, Abad-Viola G, Miranda ME, Abellanosa IP, Sadang RA et al (1992) Surveillance in evacuation camps after the eruption of Mt. Pinatubo, Philippines. MMWR CDC Surveill Summ 41:963

Ten Hoeve JE, Jacobson MZ (2012) Worldwide health effects of the Fukushima Daiichi nuclear accident. Energy Environ Sci 5:87438757. https://doi.org/10.1039/C2EE22019A

Watson JT, Gayer M, Connoly MA (2007) Epidemics after natural disasters. Emerg Infect Dis 13(1):1-5

Woersching JC, Snyder AE (2004) Earthquakes in El-Salvador: a descriptive study of health concerns in a rural community and the clinical implication: part II. Disaster Manag Response 2(1):10-13. https://doi.org/10.1016/j.dmr.2003.12.007

World Health Organization (2005) Epidemic-prone disease surveillance and response after the tsunami in Aceh Province, Indonesia. Wkly Epidemiol Record 80(18):160-164

Ye L, Kanamori H, Rivera L, Lay T, Zhou Y, Sianpar D, Satake K (2020) The 22 December 2018 tsunami from flank collapse of Anak Krakatoa volcano during eruption. Sci Adv 6(3):eaaz1377. https://doi.org/10.1126/sciadv.aaz1377

Zsceischler J et al (2018) Future climate risk from compound events. Nat Clim Change 8:469-477. https://doi.org/10.1038/s4155 8-018-0156-3

Zoraster R (2010) Vulnerable populations: hurricane katrina as a case study. Prehosp Disaster Med 25(1):74-78. https://doi.org/10.1017/ S1049023X00007718 